\title{
Perceived Health Status and Health Promoting Behaviors among University Students
}

\author{
Yo-Chan Ahn, Hyun-Suk Park, Gyu-Won Ra \\ Dept. of Health Service Management, Daejeon Univ.
}

\begin{abstract}
Objectives: This study aimed to investigate the relationship among perceived health status, dietary habit and health promoting behaviors of university students.

Methods: The subjects were 464 university students. Data were collected by using self-reported questionnaires. The results were analyzed using descriptive statistics, t-test, ANOVA, Pearson's correlation coefficient and multiple regression analysis with the PASW 18.0 program.

Results: The mean score of perceived health status was 3.24, dietary habit was 2.85 and health promoting behaviors was 2.24. There were significant differences in perceived health status according to gender, BMI, exercise and stress. There were significant differences in dietary habit according to residence, monthly allowance, drinking alcohol, exercise, sleeping hours and stress. In addition there were significant differences in health promoting behaviors according to gender, residence, BMI, smoking and exercise. Also, perceived health status significantly positively correlated between dietary habit and health promoting behaviors.

Conclusions: As the results of multiple regression analysis, the related factors of perceived health status of university students were exercise, stress and spiritual growth factor. Therefore, it is necessary to develop multiple health promoting programs considering characteristics of university students. And various strategies have been developed to increase the physical activity should be run.
\end{abstract}

$\overline{\text { Key Words }}$ : Health Status, dietary habit, Health Promoting Behavior, University Students

\section{Introduction}

College students are in adolescence, which is the early adulthood of their lifetime, and during this period, they are healthiest in such health indicators as mortality rate and incidence rate. However, as they become college students, they expose themselves to open environments and events requiring autonomy where they should make decisions on all the problems for themselves. Besides, they are given many problems regarding school adaptation, peer relations, romantic relations, future career and even clothing, food and shelter, while having more chances to form smoking and irregular eating habits caused by various outdoor activities. Furthermore, they are more likely to do unhealthy behaviors while being exposed to physical, mental and social stress ${ }^{1)}$. In the early adulthood, college students do not have stable health habits, so they are more likely to change their own health behaviors for the worse, and their health habits fixed during this period will have effect on their future health behaviors in the mid and late adulthood ${ }^{2}$.

\footnotetext{
- Received : 1 December 2014 - Revised : 23 December 2014 Accepted : 23 December 20

- Correspondence to : Hyun-Suk Park

Dept. of Health Service Management, Daejeon Univ.

62. Daehak-ro, Dong-gu, Daejeon City, 300-716 Republic of Korea

Tel : +82-42-280-2062, Fax : +82-42-280-2360, E-mail : parkhs@dju.kr
} 
To show health improvement behaviors, college students should perceive the importance of their own health in advance. Perception is an individual meaning of controling his or her behaviors, and individuals show different health behaviors depending on how much they have perceived their own health ${ }^{3}$.

According to $\mathrm{Ware}^{4)}$, health perception means an individual meaning of controlling his or her own health behaviors, which implies there is a close relation between health perception and health behaviors. Pender ${ }^{5)}$ reported that there is a correlation between a perceived health state and a health improvement lifestyle, and Singer ${ }^{6}$ said that a perceived health state has more effect on health behaviors than objective health state measurement.

$\mathrm{Seo}^{7)}$ said that health improvement behaviors are determined by psychological subjective factors, such as individuals' beliefs, values and motives, and Cockerham et al., ${ }^{8)}$ reported that it is more reliable to comprehend the degree of health improvement behaviors by using a self-evaluated perceived health state than clinical reasons. Besides, Ocampo ${ }^{9)}$ reported that one's self-reported health in the early adulthood, that is, perception of one's health is an important determinant in carrying out disease-prevention activities or doing health improvement behaviors, and it can be basic data when a differentiated and systematic health management program is planned for each subject in the future.

$\mathrm{Kim}^{10)}$ comparatively analyzed local college students' perceived health states and their health improvement behaviors by whether they live with their parents, and Yin $^{11)}$ reported the actual states of college students' drinking and its gravity. Steptoe et al., ${ }^{12)}$ discovered that in college students, health risk behaviors increase, such as adult disease-related behaviors and smoking, while health improvement behaviors decrease, such as realizing the importance of health and taking in fruits.

Thus, this study aims to investigate college students' perceived health states, eating habits and health improvement behaviors so that it may provide basic data needed to set up a direction for systematic and efficient health improvement and management for their college life and in adulthood after graduation. Concrete goals of this study can be summarized as below.

The first one is to investigate college students' general characteristics and health-related characteristics.

The second one is to investigate college students' perceived health states, eating habits and health improvement lifestyles.

The third one is to investigate college students' general characteristics and perceived health states, eating habits and health improvement lifestyles according to their health-related characteristics.

The fourth one is to investigate factors related to college students' perceived health states.

The last one is to investigate factors related to the health states perceived by subject college students.

\section{Research Methods}

This study was conducted on college students going to two-year college and four-year college in Daejeon, Chungnam and Daegu. To collect data, this study distributed copies of the questionnaire to randomly selected college students from 6 different colleges during May, 2014, and had them fill in the self-ministered and structured questionnaire. Out of all the copies of the questionnaire, this study coded and used a total of 464 copies for analysis, except the remaining 30 copies with unfaithful responses.

As general characteristics of the research subjects, this study investigated their gender, age, major, residence type, monthly allowance, and as health-related characteristics, this study investigated their height, weight, smoking, drinking, exercise, sleeping hours and stress. Their height and weight were used to calculate BMI, which was used for analysis. Besides, this study investigated their perceived health states, eating habits and health 
improvement lifestyles. A perceived health state means a human's overall wellbeing state that one can lead a daily routine for oneself while carrying out one's physical, mental and social functions properly and effectively. This study partially modified Health Self-rating Scale developed by Northern Illinois University ${ }^{13)}$ and translated by Kim and Park ${ }^{14)}$ into Korean on the scale of 5 points. In Kim and Park's research ${ }^{14)}$, Cronbach's alpha was .79 , and in this study, Cronbach's alpha was .779 . Their eating habits were given 10 questions about eating speed, imbalanced diet, skipping meals, late-night meals, eating-out, intake of processed food, under the consultation of food and nutrition professors based on the scale of 5 points. The reliability of this scale was Cronbach's alpha $=.726$.

A health improvement lifestyle means positively responding to environments for better health with continuous activities that are components of a healthy lifestyle, and it indicates behaviors to enhance one's health maintenance, self-realization and self-achievement as well as disease prevention. This study used 50 questions on the scale of 4 points from Health Promoting Lifestyle Profile-II (HPLP-II) developed by Walker et al., ${ }^{15)}$ and translated by $\mathrm{Seo}^{7)}$. In $\mathrm{Seo}^{7)}$ 's research, Cronbach's alpha was .9217 , and in this study, Cronbach's alpha was .947, and those of sub-scales, physical activity factor, nutrition factor, spiritual growth factor, interpersonal relation factor and stress management factor were $0.843, \quad 0.878, \quad 0.792, \quad 0.852, \quad 0.825$, and 0.778 respectively.

The collected data was analyzed through PASW 18.0. As concrete analysis methods, this study conducted a frequency analysis of research subjects' general characteristics and health-related characteristics. After calculating the average and standard deviation of research subjects' perceived health states, eating habits and health promotion lifestyles, this study their degrees and distribution. Then, this study compared the average and standard deviation of research subjects' perceived health states, eating habits and health improvement lifestyles by their general characteristics and health-related characteristics through t-test and ANOVA. Where there was difference, this study conducted Scheffe-test. Besides, this study analyzed the correlation between their perceived health states, eating habits and health improvement lifestyles, and to find out factors related to their perceived health states, this study conducted a multiple regression analysis with the score of their perceived health states as a dependent variable and variables showing significant differences in the multi-variate analysis and main variables, such as drinking and smoking, and sub-factors, such as eating habits and health improvement lifestyles as an independent variable.

\section{Research Results}

\section{General Characteristics and Health-related Characteristics}

Table 1 shows the research subjects' general characteristics.

Out of all the 464 respondents, there were 272 male students (58.6\%) and 192 female students (41.4\%), and their mean age was 21.6, 183 students below 20 (39.7\%), 206 students 21 to $21(44.7 \%)$ and 72 students over 24 (15.6\%). 192 students majored in humanities/social science (71.6\%), and 202 students majored in engineering, natural science and health \& medical service. 210 students lived with their parents (45.3\%), 155 lived alone (33.4\%), and 99 students lived in home-stay/dorm/relatives' place/others $(21.3 \%) .153$ students $(33.0 \%)$ received an allowance as much as 200,000 to 300,000 per month, 118 students (25.40\%) 300,000 to 400,000 won and 114 students (24.6\%) below 200,000 won per month.

BMI calculated with their height and weight was $21.4 \pm 3.5$ on average, and there were 92 students in 
the underweight group below 18.5 (19.8\%), and 131 students in the overweight group over 23 . There were 110 students smoking at present $(23.7 \%)$, and out of the non-smoking students, there were 45 ones who had experience of smoking (9.7\%) and 309 students who had no experience of smoking (66.6\%). There were 72 students not drinking (15.5\%), 223 students drinking more than once a month (48.1\%), and 169 students drinking more than once a week (36.4\%). There were 157 students not exercising at all (33.8\%), 125 students exercising more than once a month (26.9\%), and 182 students exercising more than once a week (39.2\%). There were 151 students sleeping below 5 hours (32.5\%), 162 students sleeping for 5 to 7 hours (34.9\%), and 151 students sleeping over 7 hours (32.5\%). There were 127 students not having stress at all (27.4\%), 149 students having some stress (32.1\%), and 188 students having much/very much stress $(40.5 \%)$

\section{Perceived Health States, Eating Habits and Health Improvement Lifestyles}

Table 1. General and Health Related Characteristics of Respondents

\begin{tabular}{|c|c|c|c|}
\hline Characteristics & Categories & $\mathrm{N}$ & $\%$ \\
\hline \multirow[t]{2}{*}{ Gender } & Male & 272 & 58.6 \\
\hline & Female & 192 & 41.4 \\
\hline \multirow[t]{3}{*}{ Age (years) } & $\leqq 20$ & 183 & 39.7 \\
\hline & $21 \sim 23$ & 206 & 44.7 \\
\hline & $24 \leqq$ & 72 & 15.6 \\
\hline \multirow[t]{3}{*}{ Major } & Humanities/Social sciences & 212 & 45.7 \\
\hline & Engineering/Natural science/Health care & 202 & 43.5 \\
\hline & Others & 50 & 10.8 \\
\hline \multirow[t]{3}{*}{ Residence } & Home with parents & 210 & 45.3 \\
\hline & Self-boarding & 155 & 33.4 \\
\hline & Boarding/others & 99 & 21.3 \\
\hline Monthly & $\leqq 20$ & 114 & 24.6 \\
\hline \multirow[t]{4}{*}{ allowance (10,000won) } & $20 \sim 30$ & 153 & 33.0 \\
\hline & $30 \sim 40$ & 118 & 25.4 \\
\hline & $40 \sim 50$ & 47 & 10.1 \\
\hline & $50 \leqq$ & 32 & 6.9 \\
\hline \multirow[t]{3}{*}{ BMI } & $\leqq 18.5$ & 92 & 19.8 \\
\hline & $18.5 \sim 23$ & 241 & 51.9 \\
\hline & $23 \leqq$ & 131 & 28.2 \\
\hline \multirow[t]{3}{*}{ Smoking } & Non-smoker & 309 & 66.6 \\
\hline & Ex-smoker & 45 & 9.7 \\
\hline & Current smoker & 110 & 23.7 \\
\hline \multirow[t]{3}{*}{ Drinking alcohol } & Non-drinker & 72 & 15.5 \\
\hline & $\sim$ At least once a month & 223 & 48.1 \\
\hline & At least once a week & 169 & 36.4 \\
\hline \multirow[t]{3}{*}{ Exercise } & Non-exercise & 157 & 33.8 \\
\hline & $\sim$ At least once a month & 125 & 26.9 \\
\hline & At least once a week & 182 & 39.2 \\
\hline \multirow[t]{3}{*}{ Sleeping hours } & $\leqq 5$ & 151 & 32.5 \\
\hline & $5 \sim 7$ & 162 & 34.9 \\
\hline & $7 \leqq$ & 151 & 32.5 \\
\hline \multirow[t]{3}{*}{ Stress } & Not at all/Not very & 127 & 27.4 \\
\hline & Neutral & 149 & 32.1 \\
\hline & Some/Very & 188 & 40.5 \\
\hline Total & & 464 & 100.0 \\
\hline
\end{tabular}


Table 2 shows the research subjects' perceived health states, eating habits and health improvement lifestyles.

Their perceived health states and eating habits were investigated on the scale of 5 points, and both the mean scores were $3.24 \pm 0.68$ and $2.85 \pm 0.54$ respectively. Their health improvement lifestyles were investigated on the scale of 4 points, and its mean average was $2.23 \pm 0.46$, and the interpersonal relation factor showed the highest average, $2.69 \pm 0.52$, out of all the 6 sub-scales, followed by the spiritual growth factor $2.39 \pm 0.58$, the stress management factor $2.20 \pm 0.51$, the nutrition factor
$2.16 \pm 0.53$, the physical activity factor $2.02 \pm 0.71$, and the health responsibility factor $1.88 \pm 0.57$.

\section{Perceived Health States, Eating Habits and Health Improvement Lifestyles by General Characteristics and Health-related Characteristics}

Table 3 shows the research subjects' perceived health states, eating habits and health improvement lifestyles by their general characteristics.

There was a significant difference found in gender regarding their perceived health states. Male students' mean score was $3.34 \pm 0.71$, which was significantly

Table 2. Mean scores of Perceived health status, Dietary habit and health promoting behaviors

$(\mathrm{N}=464)$

\begin{tabular}{llcc}
\hline Characteristics & Mean \pm S.D. & Min. & Max. \\
\hline Perceived health status & $3.24 \pm 0.68$ & 1.00 & 5.00 \\
Dietary habit & $2.85 \pm 0.54$ & 1.00 & 4.30 \\
Health promoting behaviors & $2.23 \pm 0.46$ & 1.00 & 4.00 \\
Health responsibility factor & $1.88 \pm 0.57$ & 1.00 & 4.00 \\
Physical activity factor & $2.02 \pm 0.71$ & 1.00 & 4.00 \\
Nutrition factor factor & $2.16 \pm 0.53$ & 1.00 & 4.00 \\
Spiritual growth factor & $2.39 \pm 0.58$ & 1.00 & 4.00 \\
Interpersonal relations factor & $2.69 \pm 0.52$ & 1.00 & 4.00 \\
Stress management factor & $2.20 \pm 0.51$ & 1.00 & 4.00 \\
\hline
\end{tabular}

Table 3. Perceived health status, Dietary habit and health promoting behaviors according to Demographic and Health Related Characteristics

\begin{tabular}{|c|c|c|c|c|c|}
\hline \multirow{3}{*}{ Characteristics } & \multirow[t]{3}{*}{ Categories } & \multirow{3}{*}{$\mathrm{N}$} & $\begin{array}{c}\text { Perceived } \\
\text { health status }\end{array}$ & Dietary habit & $\begin{array}{c}\text { Health } \\
\text { promoting } \\
\text { behaviors }\end{array}$ \\
\hline & & & Mean \pm S.D. & Mean \pm S.D. & Mean \pm S.D. \\
\hline & & & $\mathrm{t} / \mathrm{F}(\mathrm{p})$ & $\mathrm{t} / \mathrm{F}(\mathrm{p})$ & $\mathrm{t} / \mathrm{F}(\mathrm{p})$ \\
\hline \multirow[t]{3}{*}{ Gender } & Male & 272 & $3.34 \pm 0.71$ & $2.87 \pm 0.54$ & $2.31 \pm 0.46$ \\
\hline & Female & 192 & $3.10 \pm 0.63$ & $2.82 \pm 0.55$ & $2.11 \pm 0.41$ \\
\hline & & & $3.846^{* * *}$ & 0.973 & $4.966^{* * *}$ \\
\hline \multirow{4}{*}{$\begin{array}{l}\text { Age } \\
\text { (years) }\end{array}$} & $<20$ & 183 & $3.30 \pm 0.60$ & $2.92 \pm 0.49$ & $2.18 \pm 0.39$ \\
\hline & $21 \sim 23$ & 206 & $3.20 \pm 0.71$ & $2.81 \pm 0.54$ & $2.22 \pm 0.45$ \\
\hline & $24 \leq$ & 72 & $3.26 \pm 0.78$ & $2.80 \pm 0.66$ & $2.34 \pm 0.56$ \\
\hline & & & 1.070 & 2.383 & 2.950 \\
\hline \multirow[t]{4}{*}{ Major } & Humanities / Social sciences & 212 & $3.28 \pm 0.70$ & $2.84 \pm 0.55$ & $2.21 \pm 0.48$ \\
\hline & Engineering / Natural science / Health care & 202 & $3.17 \pm 0.65$ & $2.88 \pm 0.54$ & $2.26 \pm 0.40$ \\
\hline & Others & 50 & $3.36 \pm 0.77$ & $2.73 \pm 0.52$ & $2.16 \pm 0.48$ \\
\hline & & & 2.104 & 1.599 & 1.198 \\
\hline
\end{tabular}


Table 3. Perceived health status, Dietary habit and health promoting behaviors according to Demographic and Health Related Characteristics

\begin{tabular}{|c|c|c|c|c|c|}
\hline \multirow[t]{3}{*}{ Characteristics } & \multirow[t]{3}{*}{ Categories } & \multirow[t]{3}{*}{$\mathrm{N}$} & $\begin{array}{c}\text { Perceived } \\
\text { health status }\end{array}$ & Dietary habit & $\begin{array}{c}\text { Health } \\
\text { promoting } \\
\text { behaviors }\end{array}$ \\
\hline & & & Mean \pm S.D. & Mean \pm S.D. & Mean \pm S.D. \\
\hline & & & $\mathrm{t} / \mathrm{F}(\mathrm{p})$ & $\mathrm{t} / \mathrm{F}(\mathrm{p})$ & $\mathrm{t} / \mathrm{F}(\mathrm{p})$ \\
\hline \multirow[t]{4}{*}{ Residence } & Home with parents & 210 & $3.25 \pm 0.65$ & $2.89 \pm 0.54^{\mathrm{b}}$ & $2.20 \pm 0.43^{\mathrm{a}}$ \\
\hline & Self-boarding & 155 & $3.27 \pm 0.67$ & $2.73 \pm 0.52^{\mathrm{a}}$ & $2.19 \pm 0.46^{\mathrm{a}}$ \\
\hline & Boarding/others & 99 & $3.19 \pm 0.76$ & $2.94 \pm 0.56^{\mathrm{b}}$ & $2.35 \pm 0.47^{\mathrm{b}}$ \\
\hline & & & 0.516 & $6.089^{* *}$ & $5.053^{* *}$ \\
\hline \multirow{6}{*}{$\begin{array}{l}\text { Monthly } \\
\text { allowance } \\
\text { (10,000won) }\end{array}$} & $<20$ & 114 & $3.20 \pm 0.59$ & $2.96 \pm 0.49^{\mathrm{b}}$ & $2.13 \pm 0.41$ \\
\hline & $20 \sim<30$ & 153 & $3.29 \pm 0.70$ & $2.93 \pm 0.50^{\mathrm{b}}$ & $2.29 \pm 0.42$ \\
\hline & $30 \sim<40$ & 118 & $3.24 \pm 0.71$ & $2.79 \pm 0.52^{\mathrm{ab}}$ & $2.23 \pm 0.48$ \\
\hline & $40 \sim<50$ & 47 & $3.31 \pm 0.76$ & $2.62 \pm 0.59^{\mathrm{a}}$ & $2.26 \pm 0.42$ \\
\hline & $50 \leqq$ & 32 & $3.09 \pm 0.74$ & $2.58 \pm 0.72^{\mathrm{a}}$ & $2.21 \pm 0.60$ \\
\hline & & & 0.865 & $7.058^{* * *}$ & 2.197 \\
\hline \multirow[t]{4}{*}{ BMI } & $<18.5$ & 92 & $3.02 \pm 0.65^{\mathrm{a}}$ & $2.84 \pm 0.59$ & $2.15 \pm 0.42^{\mathrm{a}}$ \\
\hline & $18.5 \sim 23$ & 241 & $3.30 \pm 0.64^{\mathrm{b}}$ & $2.83 \pm 0.51$ & $2.21 \pm 0.44^{\mathrm{ab}}$ \\
\hline & $23<$ & 131 & $3.30 \pm 0.75^{\mathrm{b}}$ & $2.88 \pm 0.58$ & $2.31 \pm 0.48^{\mathrm{b}}$ \\
\hline & & & $6.414^{* *}$ & 0.273 & $3.687^{*}$ \\
\hline \multirow[t]{4}{*}{ Smoking } & Non-smoker & 309 & $3.24 \pm 0.65$ & $2.86 \pm 0.54$ & $2.18 \pm 0.42^{\mathrm{a}}$ \\
\hline & Ex-smoker & 45 & $3.45 \pm 0.90$ & $2.98 \pm 0.47$ & $2.43 \pm 0.47^{\mathrm{b}}$ \\
\hline & Current smoker & 110 & $3.17 \pm 0.67$ & $2.77 \pm 0.57$ & $2.26 \pm 0.49^{\mathrm{a}}$ \\
\hline & & & 2.731 & 2.551 & $6.476^{* *}$ \\
\hline \multirow{4}{*}{$\begin{array}{l}\text { Drinking } \\
\text { alcohol }\end{array}$} & Non-drinker & 72 & $3.07 \pm 0.84$ & $2.74 \pm 0.62^{\mathrm{a}}$ & $2.14 \pm 0.48$ \\
\hline & $\sim$ At least once a month & 223 & $3.26 \pm 0.64$ & $2.92 \pm 0.51^{\mathrm{b}}$ & $2.21 \pm 0.44$ \\
\hline & $\sim$ At least once a week & 169 & $3.30 \pm 0.67$ & $2.80 \pm 0.54^{\mathrm{ab}}$ & $2.28 \pm 0.45$ \\
\hline & & & 2.846 & $4.253^{*}$ & 2.414 \\
\hline \multirow[t]{4}{*}{ Exercise } & Non-exercise & 157 & $3.04 \pm 0.65^{\mathrm{a}}$ & $2.70 \pm 0.58^{\mathrm{a}}$ & $2.00 \pm 0.41^{\mathrm{a}}$ \\
\hline & $\sim$ At least once a month & 125 & $3.17 \pm 0.60^{\mathrm{a}}$ & $2.92 \pm 0.52^{\mathrm{b}}$ & $2.21 \pm 0.44^{\mathrm{b}}$ \\
\hline & $\sim$ At least once a week & 182 & $3.47 \pm 0.70^{\mathrm{b}}$ & $2.92 \pm 0.50^{\mathrm{b}}$ & $2.43 \pm 0.40^{\mathrm{c}}$ \\
\hline & & & $19.062^{* * *}$ & $8.975^{* * *}$ & $44.504^{* * *}$ \\
\hline \multirow{4}{*}{$\begin{array}{l}\text { Sleeping } \\
\text { hour }\end{array}$} & $<5$ & 151 & $3.18 \pm 0.70$ & $2.75 \pm 0.57^{\mathrm{a}}$ & $2.21 \pm 0.48$ \\
\hline & $5 \sim 7$ & 162 & $3.23 \pm 0.65$ & $2.93 \pm 0.48^{\mathrm{b}}$ & $2.27 \pm 0.43$ \\
\hline & $7<$ & 151 & $3.32 \pm 0.70$ & $2.85 \pm 0.56^{\mathrm{ab}}$ & $2.20 \pm 0.43$ \\
\hline & & & 1.480 & $4.490^{*}$ & 1.007 \\
\hline \multirow[t]{4}{*}{ Stress } & Not at all/Not very & 127 & $3.46 \pm 0.73^{b}$ & $2.98 \pm 0.52^{\mathrm{b}}$ & $2.24 \pm 0.46$ \\
\hline & Neutral & 149 & $3.29 \pm 0.65^{\mathrm{b}}$ & $2.84 \pm 0.54^{\mathrm{ab}}$ & $2.27 \pm 0.44$ \\
\hline & Some/Very & 188 & $3.07 \pm 0.63^{\mathrm{a}}$ & $2.76 \pm 0.54^{\mathrm{a}}$ & $2.18 \pm 0.45$ \\
\hline & & & $13.377^{* * *}$ & $5.983^{* *}$ & 1.618 \\
\hline Total & & 464 & $3.24 \pm 0.68$ & $2.85 \pm 0.54$ & $2.23 \pm 0.45$ \\
\hline
\end{tabular}

Non-respondent excluded / Post-hoc Scheffe test

$* \mathrm{p}<0.05, * * \mathrm{p}<0.01, * * * \mathrm{p}<0.001$

higher than female students', $3.10 \pm 0.63$. However, there were no differences found in age, major, residence type, and monthly allowance. Their perceived health states showed significant differences in BMI, exercise, and stress. As a result of the posttest on BMI, the low-weight group below 18.5 
showed $3.02 \pm 0.65$ on average, which was significantly lower than the normal group's and the overweight group's, $3.30 \pm 0.64$ and $3.30 \pm 0.75$ respectively. As a result of the posttest on exercise, the group exercising more than once a week showed $3.47 \pm 0.70$ on average, which was significantly higher than the group not exercising at all and the group exercising about once a month, $3.04 \pm 0.65$ and $3.17 \pm 0.60$ respectively. As a result of the posttest on stress, the group having some stress showed $3.07 \pm 0.63$, which was significantly lower than the group having normal stress an the group having no stress, $3.29 \pm 0.65$ and $3.46 \pm 0.73$ respectively.

The general characteristics significantly related to their eating habits were their residence types and monthly allowance. When their residence styles were dorm/home stay, their mean score was highest, $2.94 \pm 0.56$, followed by one's house $2.89 \pm 0.54$, and living alone $2.73 \pm 0.52$. As a result of the posttest, the living-alone group showed a significantly low score, compared to the other residence-type groups. The most allowance group showed the highest score, and as a result of the posttest, there was a significant difference between over-400,000-won group and the below-300,000-won group.

Characteristics related to their eating habits were drinking, exercise, sleeping hours and stress. As a result of the posttest on drinking, the mean score of non-drinking students was $2.74 \pm 0.62$, which was significantly lower than students drinking about once a month, $2.92 \pm 0.51$. As a result of the posttest on exercise, the mean score of the exercise group was significantly higher than that of the non-exercise group. As a result of the posttest on sleeping hours, the mean score of the group sleeping below 5 hours was significantly lower than the group sleeping for 5 to 7 hours. As a result of the posttest on stress, the mean score of the group having stress was $2.76 \pm 0.54$, which was lower than the group having no stress, $2.98 \pm 0.52$.

The general characteristics related to their health improvement lifestyles were gender and residence types. The male students' mean score was $2.31 \pm 0.46$, which was higher than the females', $2.11 \pm 0.41$. As a result of the posttest on residence types, both the one's house group and the living-alone group showed $2.20 \pm 0.43$ and $2.19 \pm 0.46$ respectively, which were significantly lower than the home-stay/dorm group's, 2.35 \pm 0.47 . The health characteristics significantly related to their health improvement lifestyles were BMI, smoking and exercise.

As a result of the posttest of BMI, the underweight group showed $2.15 \pm 0.42$, which was significantly lower than the overweight/obese group, $2.31 \pm 0.48$. In smoking, the group having experience of smoking before showed a significantly higher mean score than the non-smoking group and the group smoking at present. As a result of the posttest of exercise, the group exercising more frequently showed a higher mean score.

\section{A Correlation between Perceived Health States, Eating Habits and Health Improvement Lifestyles}

Table 4 shows the correlation between the research subjects' perceived health states, eating habits and health improvement lifestyles. All of them are in a positive correlation, and the correlation coefficient was significant.

The size of correlation coefficient between perceived health states and health improvement lifestyles $(\mathrm{r}=.322)$ was the largest, followed by that between eating habits and health improvement lifestyles $(\mathrm{r}=.308)$ and that between perceived health states and health improvement lifestyles ( $r=.196)$.

Between sub-factors of their perceived health states and health improvement lifestyles, there was a positive correlation, in order of spiritual growth factor $(\mathrm{r}=.314)$, physical activity factor $(\mathrm{r}=.290)$, stress management factor $(\mathrm{r}=.289)$, interpersonal relation factor $(\mathrm{r}=.272)$, nutrition factor $(\mathrm{r}=.221)$, and 
Table 4. Correlations among Perceived health status, Dietary habit and health promoting behaviors

\begin{tabular}{lcc}
\hline Variables & Perceived health status & Dietary habit \\
\hline Dietary habit & $.196^{* * *}$ & $.308^{* * *}$ \\
Health promoting behaviors & $.322^{* * *}$ & $.186^{* * *}$ \\
Health responsibility factor & $.151^{* * *}$ & $.236^{* * *}$ \\
Physical activity factor & $.290^{* * *}$ & $.408^{* * *}$ \\
Nutrition factor & $.221^{* * *}$ & $.206^{* * *}$ \\
Spiritual growth factor & $.314^{* * *}$ & $.153^{* * *}$ \\
Interpersonal relations factor & $.272^{* * *}$ & $.265^{* * *}$ \\
Stress management factor & $.289^{* * *}$ & \\
\hline
\end{tabular}
$* * * \mathrm{p}<0.001$

Table 5. Related Factors of Perceived health status

$(\mathrm{N}=464)$

\begin{tabular}{lcccc}
\hline Variables & $\mathrm{B}$ & $\mathrm{B}$ eta & $\mathrm{t}$ & $\mathrm{V}$ \\
\hline Gender (male=1. female=0) & .118 & .085 & 1.690 & 1.466 \\
Body Mass Index & -.001 & -.007 & -0.162 & 1.221 \\
Smoking & -.059 & -.138 & $-2.987^{* *}$ & 1.241 \\
Drinking & .065 & .090 & $2.020^{*}$ & 1.141 \\
Exercise & .070 & .182 & $3.100^{* *}$ & 1.992 \\
Stress & -.104 & -.160 & $-3.695^{* * *}$ & 1.084 \\
Dietary habit & .121 & .096 & $2.057^{*}$ & 1.261 \\
Health responsibility factor & -.063 & -.053 & -0.837 & 2.307 \\
Physical activity factor & .023 & .024 & 0.326 & 3.217 \\
Nutrition factor & -.097 & -.075 & -1.056 & 2.964 \\
Spiritual growth factor & .165 & .141 & $1.977^{*}$ & 2.938 \\
Interpersonal relations factor & .140 & .107 & 1.838 & 1.952 \\
Stress management factor & .133 & .099 & 1.385 & 2.972 \\
\hline
\end{tabular}

$\mathrm{R}^{2}=0.225$ ADJ $-\mathrm{R}^{2}=0.203 \mathrm{~F}=10.065(\mathrm{p}=.000)$

$* \mathrm{p}<0.05, * * \mathrm{p}<0.01, * * * \mathrm{p}<0.001$

health responsibility factor $(\mathrm{r}=151)$. Between sub-factors of eating habits and health improvement lifestyles, there was a positive correlation, in order of nutrition factor $(\mathrm{r}=.408)$, stress management factor $(\mathrm{r}=.265)$, physical activity factor $(\mathrm{r}=.236)$, spiritual growth factor $(\mathrm{r}=206)$, health responsibility factor $(\mathrm{r}=.186)$, and interpersonal relation factor $(\mathrm{r}=.153)$.

\section{Factors Related to Perceived Health States}

To find out factors related to the research subjects' perceived health states, this study conducted a multiple-regression analysis with the score of their perceived health states as a dependent variable and variables showing significant differences in the multi-variate analysis and main variables, such as drinking and smoking, and sub-factors, such as eating habits and health improvement lifestyles as an independent variable, and Table 7 shows the results. The regression equation was statistically significant $(\mathrm{F}=10.065, \mathrm{p}=.000)$, and there was no problem with multi-collinearity with VIF of independent variables, 2.972 , to the maximum, and the general satisfaction of independent variables could be explained up to $22.5 \%$.

As they exercise more often $(\beta=.182)$, have less 
stress $(\beta=-.160)$ and a higher score of the spiritual growth factor in their health improvement lifestyles ( $\beta=.141)$, smoke less $(\beta=-.138)$, have a higher score of the interpersonal relation factor in their health improvement lifestyles $(p=107)$ and better eating habits $(p=.096)$, they were analyzed to have a higher score of their perceived health states.

\section{Discussion}

This study aims to provide basic data needed to suggest a direction for college students to improve and manage their health systematically and efficiently during their college years and in adulthood, by investigating factors related to their perceived health states.

The mean score of the research subjects' perceived health states was $3.24 \pm 0.68$ on the scale of 5 points, which was over the medium level. It was lower than 3.42 in Hong's research ${ }^{16)}$ on nursing college students, but higher than 3.22 in Park et al.,'s research ${ }^{17)}, 3.21$ in Seo's research ${ }^{18)}$ and 3.20 in Yang and Moon's research ${ }^{19)}$ on nursing college students and even 2.72 in Kim's research on ordinary college students.

The research subjects' gender showed a significant difference in their perceived health states. The male students' score was significantly higher than female students', which shows that male students' perceived health states were better. The results of this study are the same as those of Jeong et al.,'s research ${ }^{20)}$ on ordinary college students and Hong's research ${ }^{16)}$ on nursing college students, and even the same as those of Oakley's research ${ }^{21)}$ reporting that females evaluate their health worse than males in general. The health states they perceived by the health-related characteristics showed significant differences in BMI, exercise, and stress. In smoking and drinking, the groups smoking and drinking most showed high mean scores of perceived health states $(p=0.066,0.059)$, which indicates that the more confidence they had in health, the more likely they were to smoke and drink. The characteristics significantly related to eating habits were residence types, monthly allowance, drinking, exercise, sleeping hours and stress, etc.

The research subjects' health improvement lifestyles were investigated on the scale of 4 points, and the total mean score was $2.23 \pm 0.46$. It was a little lower than 2.30 in Hong's research ${ }^{16)}$ on nursing college students, 2.36 in Hwang's research ${ }^{22)}, 2.56$ in Kim's research $^{23)}$ and 2.60 in Kim's research ${ }^{24)}$ on ordinary college students. It was even lower than 2.30 in Lee and Loke's research ${ }^{25)}$ on Hong Kong college students, but it was analyzed that they conducted medium-level health improvement behaviors in general.

Out of all the 6 sub-scales, the interpersonal relation factor showed the highest mean score, followed by the spiritual growth factor, stress management factor, nutrition factor, physical activity factor, and health responsibility factor.

The general characteristics related to their health improvement lifestyles were gender and residence types. The male students' mean score was significantly higher than the females'.

In Hong's research ${ }^{16)}$ on nursing college students, male students showed higher scores of health improvement behaviors by gender than female students, which was the same as the results of Kim's research $^{24)}$ on common college students, but contrary to the results of Kim et al.,'s research ${ }^{26)}$ and Hwang' research $^{22)}$ reporting that female students' scores of health improvement behaviors was higher than male students. In residence types, the one's house group and the living along group showed significantly lower scores than the dorm/home-stay group.

The health characteristics significantly related to college students' health improvement lifestyles were BMI, smoking and exercise. In Hong's research ${ }^{16)}$ on nursing college students, there was a statistically significant difference in the score of health improvement behaviors by whether to smoke, and 
the research subjects not smoking showed a significantly higher mean score, which was different from the results of Kim's research ${ }^{23)}$ on common college students, reporting there was no significant difference between smoking ban health improvement behaviors. In this study, the mean scores of the group having experience of smoking before and the non-smoking group were signiificantly higher than the group smoking at present, which showed rather different aspects from the results of Han and Oh et al.'s research, reporting that non-smokers and those who had smoked before showed higher scores of health improvement behaviors than those who smoked at present. It seems that those who smoked before but do not smoke at present pay more attention to health.

It was analyzed that their perceived health states have a statistically significant correlation with their health improvement behaviors. Between their perceived health improvement states and sub-factors of health improvement lifestyles, there was a positive correlation in order of spiritual growth factor, physical activity factor, stress management factor, interpersonal relation factor, nutrition factor and health responsibility factor. Even in Hong's research ${ }^{16)}$ on nursing college students, their perceived health states have a statistically significant correlation with their health improvement behaviors, and it was analyzed that out of the sub-domains of health improvement behaviors, the mental health state domain has a high correlation with the interpersonal relation domain.

So far, many previous studies on health improvement lifestyles conducted analyses by using health improvement lifestyles as a single dependent variable and various cognitive variables as an independent variable. There may be some different arguments on analysis methodology, but it seems that health-related behaviors themselves have effect on individuals' perception of their health. Accordingly, in addition to a correlation analysis, which is a kind of uni-variate analysis, this study conducted a multi-variate analysis with perceived health states as a single variable, while analyzing the correlation between sub-variables of health improvement lifestyles and main variables, such as eating habits through a multiple regression analysis. As a result of the analyses, it was found that perceived health states are closely related to the degree of exercise most, followed by the degree of stress, and the spiritual growth factor score of health improvement lifestyles, the degree of smoking, the interpersonal relation factor of health improvement lifestyles, and eating habits.

In health improvement lifestyles, college students did not put health improvement behaviors in the physical activity domain into practice, compared to the interpersonal relation domain or the spiritual growth domain. Thus, this study confirmed that it is necessary to develop and execute various different strategies good enough to increase college students' physical activities as well as their mental health states.

\section{Conclusion}

This study aims to investigate factors related to college students' perceived health states. Thus, as research subjects, this study randomly selected 464 college students in Daejeon, Chungnam and Daegu, and made them fill in self-administered and structured questionnaires. The results of this study can be summarized as below.

Firstly, the research subjects showed significant different perceived health states in gender, BMI, exercise, and stress. The mean score of male students was significantly higher than female students, and as a result of the posttest of BMI, the underweight group showed a significantly lower mean score than the normal group and the overweight/obese group. In exercise, the group exercising more showed a higher score than the group never exercising or the group 
exercising less. In stress, the group having more stress showed a lower score than the group having normal stress or the group having no stress. In drinking and smoking, the groups having smoking and drinking more showed a higher mean score $(\mathrm{p}=.066, .059)$.

The characteristics significantly related to their eating habits were residence types, monthly allowance, drinking, exercise, sleeping hours, and stress. When they lived in home-stay or dorm, they showed the highest mean score, followed by the one's house group and the living-alone group. The more monthly allowance they had, the higher score they showed. In drinking, non-drinkers showed a lower mean score than those who drank about once a month.

The characteristics significantly related to health improvement lifestyles were BMI, smoking and exercise. Male students' mean score was significantly higher than female students', and the mean score of the one's house group and the living-alone group was significantly lower than the group living in home-stay/dorm. In BMI, the underweight group showed a lower mean score than the overweight/ obese group. The group having experience of smoking before showed a significantly higher mean score than the non-smoking group and the group smoking at present. The group exercising more frequently showed a significantly higher mean score than the other groups.

Secondly, the research subjects' perceived health states had a significantly positive correlation with their health improvement lifestyles, and the correlation coefficient was significant. The size of correlation coefficient was largest between perceived health states and health improvement lifestyles $(\mathrm{r}=.322)$, followed by those between eating habits and health improvement lifestyles $(\mathrm{r}=.308)$, between perceived health states and health improvement lifestyles $(r=.196)$.

Lastly, as a result of the multiple regression analysis with the college students' perceived health state score as a dependent variable, it was found to be closely related with the degree of exercise most ( $\beta=.182$ ), followed by the degree of stress ( $\beta$ $=-.160$ ), the score of the spiritual growth factor in health improvement lifestyles $(\beta=.141)$, the degree of smoking ( $\beta=-.138$ ), the score of the interpersonal relation factor in health improvement lifestyles $(p=.107)$, and eating habits $(p=.096)$.

Based on the results above, this study discovered that exercise is most related to college students' perceived health states. In health improvement lifestyles, college students conducted least health improvement behaviors in the physical activity domain, compared to the interpersonal relation domain and the spiritual growth domain. Therefore, various different strategies should be developed and executed to increase college students' physical activities as well as improving their mental health states.

\section{Reference}

1. Kim MS. A study on the relationship between perceived health state, personality, situational barrier, health promoting behavior in students. Korean J Adult Nurs. 2004; 16(3):442-451.

2. Fardy PS, White RE, Calak LT, Amodio G, Hurster MH, McDermott MH, et al. Health promotion in minority adolescents: a health people 2000 pilot study. J Cardiopulmon Rehab. 1995; 15(1):65-72.

3. Lee HJ. An influencing health promoting behavior of perceived health status and self-efficacy according to major of college students. J Korea Acad Industr Coop Soc. 2004; 15(2);989-999.

4. Ware JE, Davies-Avery A, Donald C. Conceptualization and measurement of health for adults in the health insurance study, vol V, General health perceptions. Santa Monica, CA: Rand Corporation. 1978. 
5. Pender NJ. Health promotion in nursing practice (2nd ed.). Norwalk, CT: Appleton \& Lange. 1987.

6. Singer E, Garfinkel R, Cohen SM, Srole L. Mortality and mental health: evidence from the midtown Manhattan restudy. Soc Sci Med. 1976;10:517-525.

7. Seo HM. Construction of health promoting behavior model in elderly[dissertation]. Seoul: Seoul National Univ.; 2001.

8. Cockerham WC, Sharp K, Wilcox JA. Aging and perceived health status. J Gerontol. 1983; 38(3):349-355.

9. Ocampo JM. Self-rated health: importance of use in elderly adults. Colomb Med. 2010; 41(3):257-289.

10. Kim WS. A comparative study on the perceived health status and health promoting behaviors of college students in a suburban campus according to type of living with parents[thesis]. Seoul: Catholic Univ.; 2003.

11. In SH. A Study on the Drinking Behaviour and the Prevention of Drinking Problems of College Students: A Case Study of University A in Incheon Metropolitan City[thesis]. Incheon: Inha Univ.; 2010.

12. Steptoe A, Phill D, Wardle J, Cui J, Bellisle F, Zotti A, et al. Trends in smoking, diet, physical exercise, and attitudes toward health in European university students from 13countries, 1990-2000. Prev Med. 2002; 35:97-104.

13. Northern Illinois University. Measuring health: A guide to rating scales and questionaries. Dekalb. IL: Northern Illinois University Press. 1956.

14. Kim HJ, Park YS. Determinants of health-promoting behavior in the elderly. J Korean Acad Fundam Nurs. 1997; 4(2):283-300.

15. Walker SN, Sechrist KR, Pender NJ. The health promoting lifestyle profile II. Omaha, NE: College of nursing, University of Nebraska medical center.
1995.

16. Hong SH. The relationship between perceived health status and health promoting behaviors among nursing students. J Korean Acad Soc Nurs Educ. 2013; 19(1):78-86.

17. Park IS, Kim R, Park MH. A study of factors influencing health promoting behaviors in nursing students. J Korean Acad Soc Nurs Educ. 2007;13(2):203-211.

18. Lee IS, Lee OS. A Study on the Health Perceptions and Health Behaviors in Nursing Students. J Korean Pubilc Health Nurs. 1997; 11(1):39-50.

19. Yang NY, Moon SY. The impact of health status, health promoting behaviors, and social problem ability on college adjustment among nursing students. J Korean Acad Soc Nurs Educ. 2013; 19(1):33-42.

20. Chung YH, Seo NS, Moon SH. Related factors in health promotion behavior by gender among college students. J Korean Soc Sch Health. 2011;12(2):29-42.

21. Oakley A. Women, health and knowledge: travels through and beyond foreign parts. Health Care Women Int. 1993; 14(4):327-344.

22. Hwang HG. Factors affecting university students' health promotion behavior[dissertation]. Daegu: Daegu Hanny Univ.; 2008.

23. Kim HK. Factors influencing health promotion behaviors of university students using Pender's model. Korean J Women Health Nurs. 2006; 12(2):132-141.

24. Kim JH. A study on factors relation to health promotion behavior in collage students[thesis]. Kimhae: Inje Univ.; 2006.

25. Lee RL, Loke AJ. Health-Promoting Behaviors and Psychosocial Well-Being of University Students in Hong Kong. Public Health Nurs. 2005; 22(3):209-220. 
(480) Journal of Korean Medicine 2014;35(4)

26. Kim BK, Jung MS. Han CH. Health promoting behavior of university students and related factors. Journal of Korean society for health education and promotion. 2002; 19(1):59-85.
27. Oh NS, Park JY, Han CH. Health-promoting behaviors and related factors for college students by type of residence. J Health Educ Promot. 2011; 28(2):27-40. 